\title{
Performance and Application Analysis of Existing Energy-saving Glass
}

\author{
Nan ZHANG \\ Guangzhou Institute Building Science CO., LTD ${ }^{1}$ \\ South China University of Technology ${ }^{2}$ \\ Guangzhou, China \\ e-mail: zhangnan361@163.com \\ Ning LI \\ South China University of Technology \\ Guangzhou, China
}

\begin{abstract}
It introduces the types, energy conservation principle and application scope of the existing energy-saving glass. Energy saving glass is analyzed from different angles, and concluded glass types which are suitable for energy saving renovation of existing buildings.
\end{abstract}

Keywords-energy saving glass; building saving energy; energy saving reconstruction

\section{INTRODUCTION}

Insulating performance of windows and doors are worst in doors and windows, walls, roofs, floors four envelope member which impact building energy consumption. Doors and windows are important factors affecting indoor thermal environment and energy consumption of buildings [1]-[4].

With widespread use of glass curtain wall in public buildings and large indoor window in residential construction, glass area accounted for window area becomes more and more big. Thermal properties of glass affect the thermal performance of windows, and have a great impact on the indoor comfort. The shaded performance, insulation, and thermal performance of Single glass is poor, it will produce more energy dissipation in using process [5]-[8].

Building doors and windows are key components of the energy envelope, energy is more easily dissipated. Architectural glass thermal performance will directly affect the building energy consumption; it has a huge impact on the indoor human comfort.

\section{ENERGY-SAVING GLASS}

Energy-saving glasses are often used in Architecture at home and abroad: coated glass, film glass and heat absorbing glass. Low-E glass, film heat insulating glass and coating insulating glass are more representative in three kinds of energy-saving glass.

\section{A. Coated Glass}

Coated glass is a metal oxide film formed on the surface of the glass by coated technology. The infrared ray reflectivity of the heat reflecting coating which can effectively shield solar radiation is generally $30-60 \%$.

\author{
Xiangyang JIANG \\ Guangzhou Institute Building Science CO., LTD \\ Guangzhou, China \\ e-mail: 18126805816@163.com \\ Jiankun YANG \\ Guangzhou Institute Building Science CO., LTD \\ Guangzhou, China
}

High permeability type Low-E glass has a high transmittance, indoor day lighting effect will be good in use of this glass, especially suitable for offices, classrooms, reception room and so on. High transparent Low-E glass has a strong reflection effect in far infrared, especially for some cities in northern China. The far infrared will be again reflected back and play the effect of indoor insulation, when it encounters high permeability Low-E glass in the process of propagation.

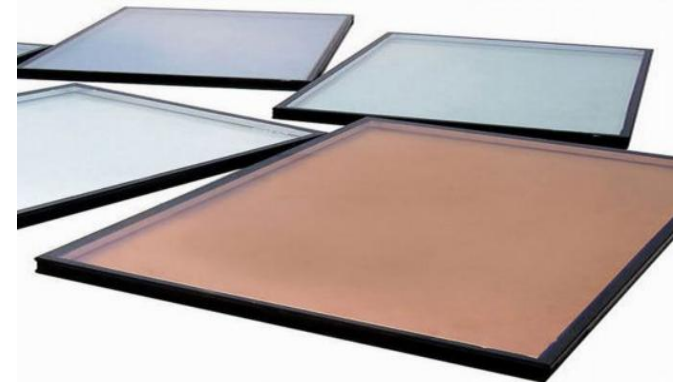

Figure 1. Coated glass

Sturdy and durable film of coated glass is easy to control by relatively high level automation equipment. Coated glass production equipment is expensive; the production line process is complex. It requires a large amount of power to guarantee the normal production and operation.

It will produce a certain scrap metal oxides and so on in coated glass production process. The wastes would damage to the environment. Coated glass is more suitable for using of new building doors and windows. Using coated glass for the building energy saving transformation is time-consuming.

Coated glass is generally processed in the factory production, and is more suitable for using of new building doors and windows. If coated glass is used for building energy-efficient transformation, it will cause the timeconsuming and money phenomenon.

Using of coated glass for doors and glass transformation, there are generally two scenarios: one is the original glass removal, handling, processing, and product of the coating glass used of original glass. The second is coated glass produced in a factory is replaced the existing building glass. 
Any of these two schemes are not completely applicable to the existing building energy saving transformation, there are some drawbacks [9]-[15].

Thus, coated glass as a building application material, coated glass is more suitable for the construction of new glass doors and windows, and is not suitable for existing building energy saving transformation.

\section{B. Film Glass}

Film glass is made of a polyester film substrate and a metal oxide adhesive composition. Film glass has good heat insulation effect. It is not only suitable for new building glass doors and windows, but also suitable for energy-saving renovation of existing buildings.

According to the energy conservation principle, film glass is divided into three kinds: patch endothermic film glass, heat reflective film glass and low emissivity foils type film glass.

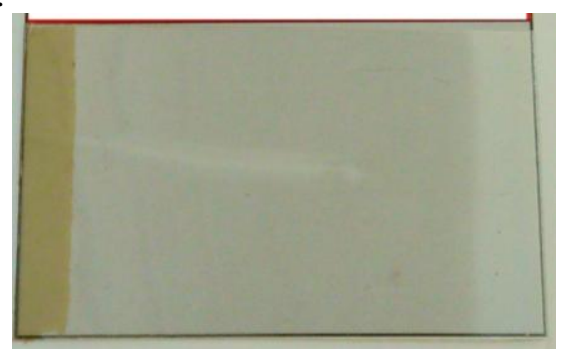

Figure2. Patch endothermic film glass

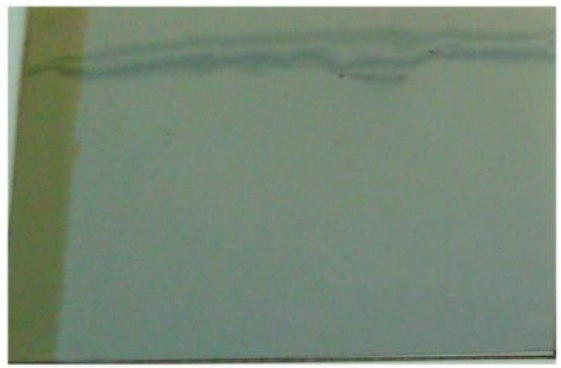

Figure 3. Heat reflective film glass

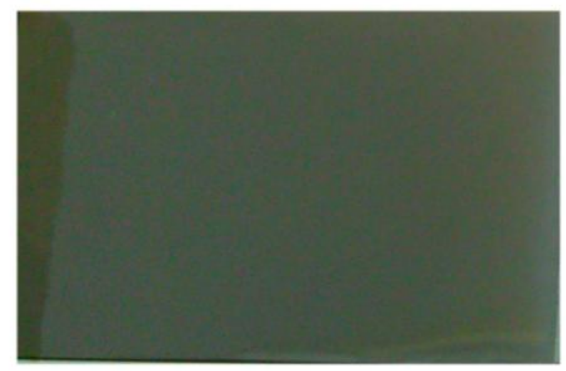

Figure 4. Low emissivity foils type film glass

Due to the addition of nonferrous metal compounds, oxides or minerals, endothermic film glass shows different color, it sometimes called the colored glass film. Film glass surface radiation rate is very low; the solar radiation absorption rate is very low. In the process of solar radiation, the temperature of glass film increase without much.

Low radiation film glass generally haves a higher visible light through rate and lower the shading coefficient. Keeping the room with full light of the circumstances, it can effectively block the sun radiation, and has good reflection effect for spectra in the far infrared radiation.

Glass film has high reflective properties; it reflects the solar spectrum to achieve energy-saving purposes. Film glass reflect the infrared ray of the sun light, it reflect the visible light in the sun light at the same time, so this film will sacrifice visible light 380-780nm band in a certain extent.

The degree of industrialized is relatively high in film glass manufacturing process. The equipment is expensive for producing film glass and production process is complicated. At present, the core technology is still sticking by big companies such as $3 \mathrm{M}$. Some of the poor quality of the glass film will appear bubble and rupture in using [15]-[20].

The film glass has good insulation effect; it can play a better effect for the control of solar radiation. It is suitable for the new building glass doors and windows energy saving, at the same time it is also very suitable for the existing building energy saving transformation.

\section{Coating Insulating Glass}

In the nineties of the last century, doors and windows white aluminum alloy frame of sapphires, emeralds and tea brown color of the endothermic glass have prevailed over a period of time, the heat absorbing glass in the absorption of solar radiation also has beautiful decoration, especially under the condition of fully closed doors and windows. It plays a good role for reducing the energy consumption of air conditioning and energy conservation.

But this colored glass is less frequency in the coastal cities of the new buildings, the reason is that various types of energy-saving glass development is very fast, appeared a lot of new energy-saving glass; second is that the visible light transmittance is generally low, in the use of the process it will affect indoor day lighting, especially the living room, balcony, shopping malls and other where need enough light.

It cannot meet the requirements of indoor lighting using the colored glass and it need to use indoor lighting which also caused the waste of electric energy in a certain extent. With the rapid development of the times, the esthetic values of people in the trend have changed a lot. The above reasons lead to the heat absorbing glass on the market greatly reduction. Of course, the heat absorbing glass doesn't completely withdraw from the construction market, especially as decorative doors and windows which can often see in the building.

When the sun radiation, the heat absorbing glass absorbs the radiation heat of the sun, reduces the solar radiation entering the room, and achieves the purpose of sun shading, but the visible light transmission rate of a certain amount is reduced at the same time.

Coating insulating glass is insulating glass with the rise of a new type of nano-dispersion technology. It has the characteristics of high visible light transmittance, low shading coefficient and good thermal insulation effect. It has 
a very good transmittance for the visible light in $380-780 \mathrm{~nm}$ band, while the infrared has a good barrier effect for more than 780nm band [21]-[26].

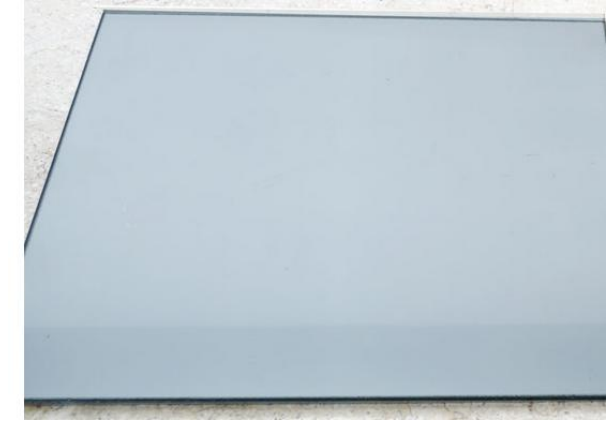

Figure 5. Coating insulating glass

Coating insulating glass is a hot spot in the application of nano materials in building energy saving. It put the heat insulation materials into the appropriate solvent and the appropriate resin with the physical dispersion and chemical dispersion.

Coating insulating glass is energy saving heat absorbing glass at home and abroad, this film insulating glass was studied such as the American Coatings Group RPM. Domestic universities and research institutes have made a lot of exploration and experimental research on the film thermal insulation glass, and successfully prepared a number of glass insulation coatings.

The production equipment of coating insulating glass is relatively low, technology is also relatively simple. Coating insulating glass can not only be used in the new building, but also be used in the existing building energy saving transformation.

\section{CONCLUDED FROM THE DIFFERENT ANGLES ABOUT ENERGY-SAVING GLASS}

Through the introduction and analysis of the above all kinds' energy-saving glass, it would be concluded from the following different angles about coated glass, film glass and coating insulating glass:

\section{A. Performance Comparison}

The performance comparison of three energy-saving glass in coated glass, film glass and coating insulating glass

The thickness of coated glass film is easy to control, the film is hard and durable with high energy efficiency and high visible light transmittance, the degree of automation of the production process is high. But its technology is complex, the price is higher, and it is not suitable for the energy saving renovation of existing buildings.

The film glass has good visible light transmittance and energy saving effect, high degree of industrialization. But equipment technical requirement is relatively high; the production process is not easy to master.

The equipment price of coating insulating glass is low, construction technology is relatively simple, especially for the existing building energy saving transformation, but there are some problems such as low hardness of the film, aging resistance weak and so on.

\section{B. The Comparison of the Whole Life Cycle for Building}

Whole life cycle of buildings are analyzed by manufacture, use and maintenance, ultimate disposal of three main links for coated glass, film glass and coated insulating glass.

Manufacturing: coated glass and film glass need to use high-end technology and higher prices of equipment, consume a large amount of power in the manufacturing process. At present, China's relatively low electricity prices and environmental costs have also caused coating, film glass projects to launch quickly. Glass coating technology and equipment is relatively simple, electric consumption is very few, the environmental pollution is small.

Use and maintenance: coated glass, film glass and coating insulating glass can meet the needs of the conventional building energy saving.

Final processing: the film and the glass is difficult to separate in the final recovery process, the technical difficulty is high, and the pollution is serious after discarded. Film and coating glass is easier to recycle.

\section{China's National Conditions}

China has a large area of existing building needed energy conservation, the task is arduous, and it needs energy saving transformation technology of building doors and windows to meet China's national conditions.

\section{APPROPRIATE GLASS TYPES}

Anti infrared, shading coefficient, visible light through rate, hardness and other performance indicators of coating insulation glass reach the requirements of the standard, Coating insulation glass could meet the needs of the construction energy-efficient transformation. It is one of appropriate affordable technology, especially suitable for existing buildings.

Coating insulating glass applied appropriate circumstances would create greater economic value, social value and environmental value in the process of localization.

\section{ACKNOWLEDGMENT}

This research is supported by Natural Science Foundation of Guangdong Province (NO.2014A030310296), National Natural Science Foundation of China (NO.51608205), Pearl River Nova Program of Guangzhou and Science Development Foundation of Guangzhou Institute of Building.

\section{REFERENCES}

[1] Tu Xiang Xiang, "China building energy saving 60 years," urban residential, 2009 (10): 76-79.

[2] Tu Xiang Xiang, "Building energy efficiency - China building energy conservation strategy of the inevitable choice," energy saving and environmental protection, 2004 (8): 15-18.

[3] Tu Xiang Xiang, "Building energy conservation situation and policy,'housing industry, 2006 (12): 34-37.

[4] Qiu. Study, "on six major areas of ," city and Countermeasures of development of building energy saving Chinese, 2010 (4): 16-19.

[5] Jiang Yi, “China's building energy consumption status and effective way of energy saving,'HVAC, 2005, 35 (5): 30-40. 
[6] Chen Weike, Luo Fang, "Analysis of the evaluation index system of China's macro building energy consumption," building economy, 2008 (2): 76-79.

[7] Li Zhaojian, Jiang Yi, "Analysis and Thinking on the status of China's building energy consumption in China,"Journal of architecture, 2006 (7): 30-33.

[8] Lin Caifu, "Practice of building energy saving reconstruction for existing buildings,"Tianjin science and technology, 2006 (1): 15.

[9] "The proportion of building energy consumption and long Mei V C building energy-saving target," China energy, 2005 (10): 23-27.

[10] Lang four, "The public building energy efficiency design standards publicizing materials," Beijing: Chinese Building Industry Press, 2005.

[11] Jiang Yi, "China's building energy consumption status and building energy conservation work in China,"China Construction, 2006, 13 (2): 12-18.

[12] Luo Shuxiang, "The influence of thermal performance of windows and doors glass on building energy consumption," building energy efficiency, 2009 (11): 42-46.

[13] Wang Jianhua, "Problems and technical measures for energy conservation of Building Exterior Windows,"industrial building, 2006 (36): 8-13.

[14] Yu Shanqing, "Energy saving materials and technology for windows ," new building materials, 1999, (7): 24-25.

[15] Huang Dong Xia, "Energy and environmental impact," windows and window glass of building energy conservation, 2008 (4): 99-100.
[16] Yang Zijiang. Key, "renewable energy for energy saving building," doors and windows, 2004 (4): 52-54

[17] YuWenGong, "Window energy saving analysis," Energy saving, 2005, (2): 32-34.

[18] Every auspicious, "Energy-saving window technology," Beijing, China building industry press, 2003.

[19] Yu Shanqing, "Windows energy-saving materials and technology," Journal of new building materials, 1999 (7): 24-25.

[20] Yang Yanping, "Hot summer and cold winter region both energysaving reform," Journal of building doors and Windows of new building materials, 2007 (9): 40-43.

[21] Tan Liangcai, hong-xing Yang et al, "Dynamic energy-saving Windows in hot summer and cold winter region and economy research," Journal of hvac, 2004 (8): 1-6.

[22] Yangtze Jiang, "In hot summer and cold winter region small town residential doors and Windows energy saving technical measures," Industrial construction, 2005 (7): 19-22.

[23] Jin Jiong, "The preparation of low radiation glass research," Zhejiang: zhejiang university, 2005.

[24] Yang Yunhua, "Energy-saving performance of low radiation glass research," Journal of solar energy, 2001 (7): 296-300.

[25] Rui-hong Zhang, "Vacuum flat glass heat transfer performance and support research," Beijing: China agricultural university, 2006.

[26] Shu-ting Tong, "Low emissivity coating glass surface numerical simulation of thermal radiation," Journal of building materials, 2002 (5) : 60-65 